\section{Strategies for new understanding of and new hope for mental health}

Key words: mental health, mental disorders, health services, World Health Organization.

\footnotetext{
1 Based on: World Health Organization. World health report 2001: mental health: new understanding, new hope. Geneva: WHO; 2001. Available from: http://www.who.int/whr [Internet site]. Accessed 13 December 2001.
}

Mental health is as important as physical health to the overall well-being of individuals, societies, and countries. In spite of that, only a small minority of the 450 million people around the world who suffer from a mental or behavioral disorder receive even the most basic treatment. To help address that imbalance, the World Health Organization (WHO) chose to focus its World Health Report 2001 on new hope and new understanding for mental health.

In most parts of the world, the WHO report says, mental health and mental disorders are not regarded with anything like the same importance as physical health. Instead, they have been largely ignored or neglected. Partly as a result, the world is suffering from an increasing burden of mental disorders, and a widening "treatment gap." In developing countries most individuals with severe mental disorders are left to cope as best they can with their private burdens such as depression, dementia, schizophrenia, and substance dependence and abuse. Much of the same is true for such other disorders as epilepsy, Alzheimer's disease, and mental retardation as well as for disorders of childhood and adolescence, including dyslexia, autism, attention deficit/hyperactivity disorders (ADHD), and conduct disorders. Around the world, many of the people suffering from mental or behavioral disorders are victimized for their illness and become the targets of stigma and discrimination.

Further increases in the number of sufferers are likely, given the aging of the world population, worsening social problems, and civil unrest. Mental disorders already represent 4 of the 10 leading causes of disability worldwide. This growing burden amounts to a huge cost in terms of human misery, disability, and economic loss.

There is a disproportionate relationship between disease burden and disease spending. Mental and behavioral disorders are estimated to account for $12 \%$ of the global burden of disease, yet the mental health budgets of the majority of countries constitute less than $1 \%$ of their total health expenditures. Further, more than $40 \%$ of countries have no mental health policy, and over $30 \%$ have no mental health program. Over $90 \%$ of countries have no mental health policy that includes children and adolescents. Moreover, health insurance plans and other medical care schemes frequently do not cover mental and behavioral disorders at the same level as other illnesses, creating significant economic difficulties for patients and their families. 


\section{Overall recommendations from the WHO report}

In its World Health Report 2001 the World Health Organization (WHO) makes a set of 10 overall recommendations for steps that nations can take to promote better understanding of and increased hope for mental health.

\section{Provide treatment in primary care}

The management and treatment of mental disorders in primary care is a fundamental step that enables the largest number of people to get easier and faster access to services. For this to happen, however, general health personnel need to be trained in the essential skills of mental health care. Such training ensures the best use of available knowledge for the largest number of people and makes possible the immediate application of interventions. Mental health should therefore be included in training curricula, with refresher courses to improve the effectiveness of the management of mental disorders in general health services.

\section{Make psychotropic drugs available}

Essential psychotropic drugs should be available at all levels of health care. These medicines should be included in every country's essential drugs list, and the best drugs to treat conditions should be made available whenever possible. These drugs can ameliorate symptoms, reduce disability, shorten the course of many disorders, and prevent relapse. The drugs often provide the first-line treatment, especially in situations where psychosocial interventions and highly skilled professionals are unavailable.

\section{Give care in the community}

Community care has a better effect than does institutional treatment on the outcome and quality of life of individuals with chronic mental disorders. Shifting patients from mental hospitals to care in the community is also cost-effective and respects human rights. Mental health services should therefore be provided in the community, with the use of all available resources. Community-based services can lead to early intervention and limit the stigma of being treated. Large custodial mental hospitals should be replaced by community care facilities, backed by general hospital psychiatric beds and home care support. This shift towards community care requires health workers and rehabilitation services to be available at the community level, along with crisis support, protected housing, and sheltered employment.

\section{Educate the public}

Public education and awareness campaigns on mental health should be launched in all countries. The main goal is to reduce barriers to treatment and care by increasing awareness of the frequency of mental disorders, their treatability, the recovery process, and the human rights of people with mental disorders. Information on the care choices available and their benefits should be widely disseminated so that responses from the general population, professionals, media, policymakers, and politicians reflect the best available knowledge. Well-planned public awareness and education campaigns can reduce stigma and discrimination, increase the use of mental health services, and better integrate mental and physical health care.

\section{Involve communities, families, and consumers}

Communities, families, and consumers should be included in the development of and decisionmaking on policies, programs, and services. To better tailor services to people's needs, interventions should take account of age, sex, culture, and social conditions.

\section{Establish national policies, programs, and legislation}

Mental health policy, programs, and legislation are necessary steps for significant and sustained action. These should be based on current knowledge and human rights considerations. Most countries need to increase their budgets for mental health programs from existing low levels. Mental health reforms should be part of larger health system reforms. Health insurance programs should not dis- 
criminate against persons with mental disorders, thus broadening access to treatment and reducing the burden of care.

\section{Develop human resources}

Most developing countries need to increase and improve training of mental health professionals, who will both provide specialized care and support primary health care programs. Most developing countries lack an adequate number of such specialists to staff mental health services. Once trained, these professionals should be encouraged to remain in their country in positions that make the best use of their skills. This human resource development is especially necessary for countries with few resources at present. Though primary care provides the most useful setting for initial care, specialists are needed to provide a wider range of services. Specialist mental health care teams ideally should incorporate both medical and nonmedical professionals, including psychiatrists, clinical psychologists, psychiatric nurses, psychiatric social workers, and occupational therapists, who can work together towards the total care and integration of patients in the community.

\section{Link with other sectors}

Sectors other than health, such as education, labor, welfare, and law, should be involved in improving the mental health of communities. Nongovernmen- tal organizations should be much more proactive, should have better-defined roles, and should provide greater support to local initiatives.

\section{Monitor community mental health}

The mental health of communities should be monitored by including mental health indicators in health information and reporting systems. The indices should include both the numbers of individuals with mental disorders and the quality of their care, as well as some more general measures of the mental health of communities. Such monitoring helps to determine trends and to detect mental health changes resulting from disasters and other external events. Monitoring is necessary to assess the effectiveness of mental health prevention and treatment programs, and it also strengthens arguments for the provision of more resources.

\section{Support more research}

More research into biological and psychosocial aspects of mental health is needed in order to increase the understanding of mental disorders and to develop more effective interventions. Such research should be carried out on a wide international basis to understand variations across communities and to learn more about factors that influence the cause, course, and outcome of mental disorders. Building research capacity in developing countries is an urgent need.
The full WHO report presents extensive information concerning the current understanding of mental and behavioral disorders, their magnitude and burden, effective treatment strategies, and strategies for enhancing mental health through policy and service development.

The report emphasizes that governments are as responsible for the mental health as for the physical health of their citizens. As the ultimate stewards of any health system, governments must take the responsibility for ensuring that mental health policies are developed and implemented. The report recommends a set of 10 key strategies for countries to undertake (see the sidebar entitled "Overall recommendations").

\section{ACTION BASED ON DIFFERING LEVELS OF RESOURCES}

While they are generally applicable, a number of the recommendations in the WHO report may appear to be far beyond the resources of many countries. Nevertheless, even nations with limited resources could implement some of the suggested steps, and the same is true for disadvantaged areas or groups in a country with more resources, such as with rural populations or indigenous groups.

In low-income countries where mental health resources are completely absent or very limited, it is possible to immediately recognize mental health as an integral part of general health and to begin to 


\section{In the United States of America disparities exist in mental health services for racial and ethnic minorities}

In spite of the massive and growing spending on health care services in the United States of America, there are still large differences in the access to and the quality of mental health services for racial and ethnic minority populations as compared to other groups in the country, according to a report issued in August 2001 by Dr. David Satcher, the Surgeon General of the United States. The surgeon general is an official of the United States Government who serves as the nation's leading spokesperson in advocating on issues of public health.

The new report, entitled Mental Health: Culture, Race and Ethnicity, is a supplement to a 1999 report on mental health that the Surgeon General produced. The new document focuses on four racial and ethnic minority groups in the United States: African-Americans, Hispanic Americans, AsianAmericans and Pacific Islanders, and American Indians and Alaska Natives. The report highlights the role that culture and society play in mental health, mental illness, and the types of mental health services that people seek.

Culture influences many aspects of mental illness and mental health, according to the report. Culture affects how patients communicate and manifest their symptoms, how they cope, the range of their family and community supports, and their willingness to seek treatment.

The report finds that, although effective, welldocumented treatments for mental illnesses are available in the United States, racial and ethnic minorities are less likely than the general population to receive quality care. Minority groups in the United States have the same overall prevalence of mental disorders as do white Americans. Among the entire population, only one in three persons who need mental health services currently receives care. This proportion is even lower in some minority populations. African-Americans are about half as likely as the rest of the population to seek mental health services, and Asian-Americans are only about one-fourth as likely.

Various reasons contribute to minority groups' decreased access to and utilization of mental health services, according to the report. These include fewer minority persons' having health insurance that would cover the cost of such services, lack of money to pay for the services on their own, cultural differences, the stigma attached to mental illness, language barriers for persons with limited English, and a shortage of mental health professionals from minority groups.

The report makes a number of recommendations. Among these are that more research needs to be done on the link between culture and mental health, that more mental health specialists from minority groups need to be trained, and that mental health care should take more of a communitybased approach.

The full report can be viewed for free on the Internet at: http://www.surgeongeneral.gov/library/ mentalhealth. Interested persons can also ask for a single copy of the report for free by sending a request by postal mail to Knowledge Exchange Network (KEN), P.O. Box 42490, Washington, D.C. 20015, United States of America; by fax to (301) 9848796; by e-mail to ken@mentalhealth.org; or by telephoning (within the United States) (800) 789-2647. organize the basic mental health services as a part of primary health care. This need not be a costly exercise, and it would be greatly enhanced by providing essential neuropsychiatric drugs as well as inservice training of all general health personnel.

In countries with a medium level of resources, some resources are generally available for mental health, such as centers for treatment in big cities or pilot programs for community care. But these resources do not provide even essential mental health services to the total population. These countries are likely to have mental health policies, programs, and legislation, but these measures are often not fully implemented. For these nations the immediate action should be to enlarge mental health services to cover the total population. This can be done by extending 
training to all health personnel on essential mental health care, providing neuropsychiatric drugs in all health facilities, and bringing all of these activities under a mental health policy. Custodial hospitals should be closed down and replaced with community care facilities. Mental health care can be introduced in workplaces and schools.

In industrialized countries with a relatively high level of resources for mental health, the most important step is to increase public awareness, particularly in order to decrease stigma and discrimination. The newer medicines and psychosocial interventions should be made available as part of routine mental health care. Mental health information systems should be developed. Research should be initiated or extended on cost-effectiveness, prevention of mental disorders, and the causes of mental disorders.

\section{SINOPSIS}

\section{Estrategias del informe de la OMS "Salud mental: nuevos conocimientos y nuevas esperanzas"}

La salud mental es tan importante como la salud física para el bienestar general de las personas, las sociedades y los países. A pesar de ello, solo una pequeña proporción de la población mundial con trastornos mentales o conductuales recibe tratamiento, aunque sea el más básico. Para ayudar a abordar este desequilibrio, la Organización Mundial de la Salud (OMS) decidió centrar su Informe sobre la Salud en el Mundo, 2001 en las nuevas esperanzas y los nuevos conocimientos acerca de la salud mental. El informe de la OMS presenta información sobre los conocimientos actuales de los trastornos mentales y de la conducta, su magnitud y carga, las estrategias terapéuticas eficaces y las estrategias para mejorar la salud mental mediante el desarrollo de políticas y servicios. Se hacen 10 recomendaciones generales para los países, entre las que se encuentran las siguientes: tratar los trastornos mentales en el ámbito de la atención primaria; hacer que los fármacos psicotrópicos esenciales estén disponibles en todos los niveles de la atención sanitaria; proporcionar la asistencia en la comunidad, y no en instituciones, y lanzar campañas de educación y concienciación pública acerca de la salud mental. Hasta los países con escasos recursos podrían poner en práctica algunas de estas sugerencias, y lo mismo ocurre con las áreas o grupos desfavorecidos, como las poblaciones rurales o indígenas de países con más recursos. Entre las medidas más esenciales está el reconocimiento inmediato de la salud mental como parte integral de la salud general y la organización de servicios básicos de salud mental como parte de la atención primaria.

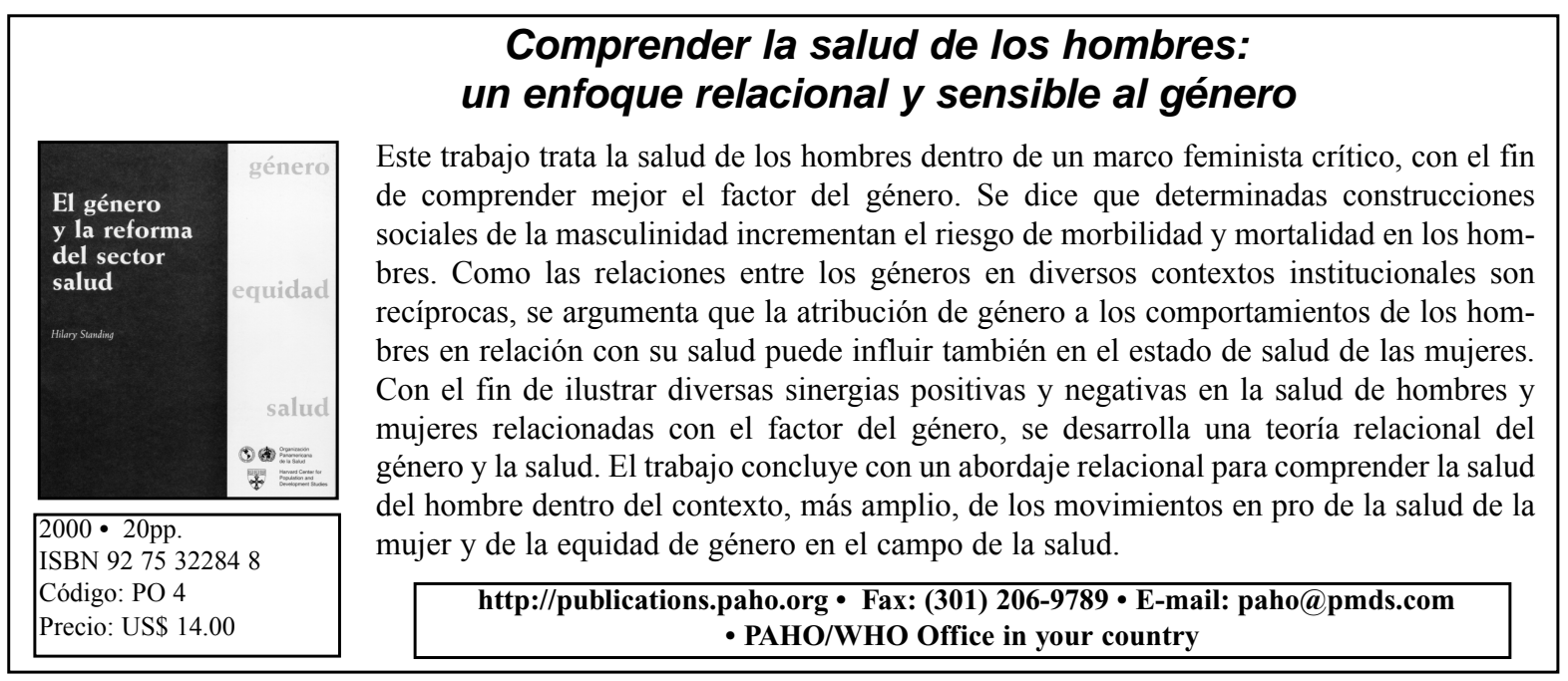

